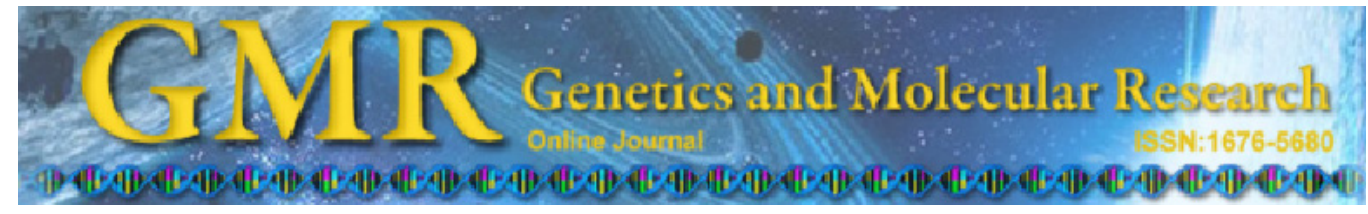

\title{
Diversity of propanil-degrading bacteria isolated from rice rhizosphere and their potential for plant growth promotion
}

\author{
A.R.L. Procópio ${ }^{1}$, R.E.L. Procópio ${ }^{2}$, A.A. Pizzirani-Kleiner ${ }^{2}$ and \\ I.S. Melo ${ }^{1}$ \\ ${ }^{1}$ Embrapa Meio Ambiente, Jaguariúna, SP, Brasil \\ ${ }^{2}$ Universidade de São Paulo, Escola Superior de Agricultura "Luiz de Queiroz", \\ Departamento de Genética, Piracicaba, SP, Brasil \\ Corresponding author: I.S. Melo \\ E-mail: itamar@cnpma.embrapa.br
}

Genet. Mol. Res. 11 (3): 2021-2034 (2012)

Received October 6, 2011

Accepted March 9, 2012

Published August 6, 2012

DOI http://dx.doi.org/10.4238/2012.August.6.6

\begin{abstract}
The herbicide propanil has long been used in rice production in southern Brazil. Bacteria isolated from contaminated soils in Massaranduba, Santa Catarina, Brazil, were found to be able to grow in the presence of propanil, using this compound as a carbon source. Thirty strains were identified as Pseudomonas (86.7\%), Serratia (10.0\%), and Acinetobacter (3.3\%), based on phylogenetic analysis of $16 \mathrm{~S}$ rDNA. Little genetic diversity was found within species, more than $95 \%$ homology, suggesting that there is selective pressure to metabolize propanil in the microbial community. Two strains of Pseudomonas (AF7 and $\mathrm{AF} 1)$ were selected in bioreactor containing chemotactic growth medium, with the highest degradation activity of propanil exhibited by strain AF7, followed by AF1 (60 and 40\%, respectively). These strains when encapsulated in alginate exhibited a high survival rate and were able to colonize the rice root surfaces. Inoculation with Pseudomonas strains AF7 and AF1 significantly improved the plant height of rice. Most of the Pseudomonas strains produced indoleacetic acid, soluble mineral phosphate, and fixed nitrogen. These bacterial strains could
\end{abstract}


potentially be used for the bioremediation of propanil-contaminated soils and the promotion of plant growth.

Key words: Biodegradation; Pseudomonas; Propanil

\section{INTRODUCTION}

Propanil is used to control a wide variety of grasses and broad-leaved and aquatic weeds in southern Brazil. Propanil, or propanide ( $3^{\prime}, 4^{\prime}$-dichloropropionanilide), is a contact herbicide that is used worldwide to control weeds by inhibiting photosynthesis. The compound is widely used in agriculture for post-emergence weed control when growing a large variety of crops, including rice, wheat, barley, oats, and rye, but propanil is known to be toxic (Pichon et al., 2004). Bioremediation is a process that involves the use of microbes to detoxify and degrade pollutants. Bioremediation has received considerable attention as an effective biotechnological approach for cleaning up polluted environments. Concern over the potential risks posed by pesticide residues to environmental and human health has increased the demand for the development of bioremediation strategies for the detoxification of herbicides by microorganisms. Studies of microbial degradation are useful for the development of bioremediation processes to detoxify herbicides to concentrations lower than the standards established by regulatory authorities (Vidali, 2001). The bacterial genus Pseudomonas plays an important role in many ecosystems due to its metabolic versatility and ability to degrade xenobiotic compounds (Tidswell et al., 1996). Pseudomonas spp have been studied primarily because of their widespread distribution in the soil, their ability to colonize the rhizosphere of host plants, and their ability to antagonize phytopathogens, thus promoting plant growth. The main focus of this study was to assess the genetic structure of the bacterial population in the rhizosphere of Oryza sativa in soil that has been treated with propanil for an extended period of time. We also examined the isolate AF7 as an inoculant in the rhizosphere of a host plant.

\section{MATERIAL AND METHODS}

\section{Isolation of strains}

The bacterial (psychrotrophic) strains used in this study were isolated from naturally propanil-contaminated soil (rice rhizosphere) in Massaranduba, Santa Catarina, Brazil. This site has a history of application of the herbicide propanil for over 20 years.

\section{Bacteria can grow in the presence of propanil}

One gram of soil was added to an Erlenmeyer flask $(25 \mathrm{~mL})$ containing $9 \mathrm{~mL} 0.1 \mathrm{M}$ $\mathrm{MgSO}_{4}$. The soil suspension was serially diluted, and appropriate dilutions were plated on King's B agar medium supplemented with $25 \mu \mathrm{g} / \mathrm{mL}$ propanil.

\section{Bacteria are capable of using propanil as a carbon source}

Several rhizosphere soil samples (10 g each) were collected and homogenized. A total 
of $200 \mathrm{~g}$ was added to a 5.0-L bioreactor containing chemotactic growth medium $(2.75 \mathrm{~g} / \mathrm{L}$ $\mathrm{K}_{2} \mathrm{HPO}_{4} ; 1.0 \mathrm{~g} / \mathrm{L}\left(\mathrm{NH}_{4}\right)_{2} \mathrm{SO}_{4} ; 0.2 \mathrm{~g} / \mathrm{L} \mathrm{MgCl} 2.6 \mathrm{H}_{2} \mathrm{O} ; 0.1 \mathrm{~g} / \mathrm{L} \mathrm{NaCl} ; 0.02 \mathrm{~g} / \mathrm{L} \mathrm{FeCl} \cdot 6 \mathrm{H}_{2} \mathrm{O} ; 0.01$ $\mathrm{g} / \mathrm{L} \mathrm{CaCl}$, and $1 \mathrm{~mL}$ trace elements $\left[1 \mathrm{mg} / \mathrm{L} \mathrm{H}_{2} \mathrm{BO}_{3} ; 0.8 \mathrm{mg} / \mathrm{L} \mathrm{MnSO}_{4} ; 0.6 \mathrm{mg} / \mathrm{L} \mathrm{ZnSO}_{4} \cdot 7 \mathrm{H}_{2} \mathrm{O}\right.$; $0.025 \mathrm{mg} / \mathrm{L} \mathrm{CuSO}_{4} .5 \mathrm{H}_{2} \mathrm{O}$, and $\left.\left.0.001 \mathrm{mg} / \mathrm{L} \mathrm{CaSO}_{4} .7 \mathrm{H}_{2} \mathrm{O}\right]\right)$. The final $\mathrm{pH}$ was adjusted to 7.2 .

\section{After autoclaving}

After autoclaving at $121^{\circ} \mathrm{C}$ for $20 \mathrm{~min}$ and cooling, the medium was supplemented with $100 \mu \mathrm{g} / \mathrm{mL}$ propanil as the sole carbon source. The sample was then incubated for 7 days at $28^{\circ} \mathrm{C}$. Afterwards, $100 \mathrm{~mL}$ fermentation solution was removed and reintroduced into a bioreactor containing chemotactic growth medium. After three rounds of fermentation, the bacterial suspension was diluted and plated on solid chemotactic medium containing $25 \mu \mathrm{g} /$ $\mathrm{mL}$ propanil.

\section{Identification of isolates}

The identification of isolated strains was performed according to Bergey's Manual of Determinative Bacteriology (Bergey et al., 1984). Genomic DNA was extracted by a beadbeating lysis method with $10 \%$ sodium dodecyl sulfate and phenol-chloroform. The $16 \mathrm{~S}$ rRNA gene was amplified by PCR using the universal primers 27F (5'-GAGAGTTTGATCCTGGCT CAG-3') and 1401R (5'-CGGTGTGTACAAGGCCCGGGAACG-3').

The PCR conditions were: $95^{\circ} \mathrm{C}$ for 5 min followed by 30 cycles of $94^{\circ} \mathrm{C}$ for $1 \mathrm{~min}$, $55^{\circ} \mathrm{C}$ for $1 \mathrm{~min}$, and $72^{\circ} \mathrm{C}$ for $1 \mathrm{~min} 30 \mathrm{~s}$, and a final step at $72^{\circ} \mathrm{C}$ for $10 \mathrm{~min}$. Subsequently, the DNA amplification product was purified (GFX PCR kit, Amersham Pharmacia Biotech) and sequenced. The partial 16S rDNA sequence obtained was submitted to GenBank for BLAST searching, and phylogenetic analyses were conducted using MEGA4 (Tamura et al., 2007).

\section{Biodegradation study}

For degradation assays, selected strains (AF1 and AF7) were grown in $50 \mathrm{~mL}$ chemostactic growth medium with propanil at $25 \mu \mathrm{g} / \mathrm{mL}$ as the sole carbon source for 15 days in a shaker at $120 \mathrm{rpm}$ and a temperature of $28^{\circ} \mathrm{C}$. Culture samples were then thawed, centrifuged (6000 $\mathrm{g}, 1 \mathrm{~min}$ ), and filtered through $0.2-\mu \mathrm{m}$ pore size membranes. For propanil extraction from liquid cultures, $5 \mathrm{~mL}$ supernatant was extracted with $30 \mathrm{~mL}$ acetone-dichloromethane (1:1). Next, the extract was evaporated to dryness at $42^{\circ} \mathrm{C}$ using a rotary vacuum evaporator and analyzed by HPLC (HP 5690) using a J\&W scientific DB-5 column (30 cm x $0.530 \mu \mathrm{m} \mathrm{x}$ $1.5 \mu \mathrm{m})$ and an $\operatorname{ECD}(300 \mathrm{C})$ detector.

\section{Screening for mineral phosphate solubilization}

Mineral phosphate solubilization activity was assayed according to Kuklinsky-Sobral et al. (2004). Briefly, bacterial strains were plated on agar medium containing inorganic phosphate $\left(15 \mathrm{~g} / \mathrm{L}\right.$ agar; $10 \mathrm{~g} / \mathrm{L}$ glucose; $5 \mathrm{~g} / \mathrm{L} \mathrm{NH}_{4} \mathrm{Cl} ; 1 \mathrm{~g} / \mathrm{L} \mathrm{NaCl} ; 1 \mathrm{~g} / \mathrm{L} \mathrm{MgSO}_{4} .7 \mathrm{H}_{2} \mathrm{O} ; 0.8 \mathrm{~g} / \mathrm{L}$ $\left.\mathrm{Ca}_{3}\left(\mathrm{HPO}_{4}\right)_{2} ; \mathrm{pH} 7.2\right)$ and incubated at $28^{\circ} \mathrm{C}$ for $48 \mathrm{~h}$. Solubilization of the mineral phosphate was indicated by clear haloes around the bacterial strains. 


\section{Screening for indoleacetic acid production}

Indoleacetic acid (IAA) production was analyzed using a modification of the qualitative method developed by Kuklinsky-Sobral et al. (2004). Sixteen strains were plated on $10 \%$ tryptic soy agar (TSA) supplemented with $5 \mathrm{mM}$ L-tryptophan, overlaid with a nitrocellulose membrane (Amersham Pharmacia) and incubated at $28^{\circ} \mathrm{C}$ for $24 \mathrm{~h}$. After bacterial growth, the membrane was removed from the plate and treated with the Salkowski reagent $[2 \%(\mathrm{w} / \mathrm{v})$ $0.5 \mathrm{M} \mathrm{FeCl}_{3}$ in $35 \%$ perchloric acid] for $15 \mathrm{~min}$ at room temperature. Bacteria producing IAA were identified by the presence of a red halo on the membrane corresponding to the position of the IAA-producing colony.

\section{Screening for nitrogen fixation}

The ability to fix nitrogen was evaluated by growing the bacterial strains in semisolid nitrogen-free NFb medium (Dobereiner et al., 1995). The bacteria that grew in this medium were subcultured in the same medium. Three cycles of growth indicated nitrogen-fixing activity.

\section{Plant growth and greenhouse inoculation}

These experiments were conducted in a greenhouse at conditions using two Pseudomonas strains AF7 and AF1. Uninoculated controls and plants inoculated with Acinetobacter sp A1 were included for comparison. Oryza sativa seeds were surface sterilized with $70 \%$ alcohol for $1 \mathrm{~min}, 2 \%$ sodium hypochlorite for $10 \mathrm{~min}$, and 70\% alcohol for $1 \mathrm{~min}$. The seeds were then washed three times with sterile distilled water and inoculated with each strain. The bacterial strains were grown in $20 \mathrm{~mL}$ trypticase soy broth (TSB) for $24 \mathrm{~h}$ at $28^{\circ} \mathrm{C}$, and then centrifuged at $4000 \mathrm{~g}$ for $10 \mathrm{~min}$. Pellets were suspended in $0.85 \% \mathrm{NaCl}$ (to an $\mathrm{OD}_{530}$ of 0.9 ). The bacterial suspensions were individually mixed with carboxymethylcellulose $(1: 1 \mathrm{w} / \mathrm{v})$ to a density of approximately $10^{7} \mathrm{CFU} / \mathrm{g}$ of carboxymethylcellulose bacterial inoculants. The seedlings were grown in a greenhouse under natural light, which provided a 15 -h photoperiod, with a temperature of $16^{\circ}$ to $25^{\circ} \mathrm{C}$ and a relative humidity of $55 \%$. The growth substrate was latosol and sand at a 3:1 ratio with propanil added at to a concentration of $0,2.5$ (field concentration), or $25 \mu \mathrm{g} / \mathrm{mL}$. The plants were subsequently removed from the tubes and washed in running water. Every plant was analyzed for the following variables: root number, length and dry weight, number of leaves, petiole length and dry weight of shoots. The mean calculated values for each estimated parameter were statistically compared using standard procedures, including the SAS general linear model and least significant difference analysis at the $5 \%$ level of probability (SAS Version 8.01, SAS Institute, Inc., Cary, NC, USA).

\section{Fluorescent labeling of Pseudomonas strain AF7}

The pCM88 vector carrying $g f p$ and kanamycin marker genes (kindly provided by Mary E. Lidstrom) was introduced into AF7 according to the protocol described by Andreote et al. (2004). Wild-type strain AF7 was grown in King's B medium (Ma et al., 2009) in 5-mL cultures at $28^{\circ} \mathrm{C}$ to an $\mathrm{OD}_{600}$. The bacterial cells were then pelleted by centrifugation $(3000$ $\mathrm{g}, 10 \mathrm{~min}, 4^{\circ} \mathrm{C}$ ), washed three times with ice-cold distilled water, and resuspended in $500 \mu \mathrm{L}$ 
ice-cold glycerol. To each $100-\mu \mathrm{L}$ cell suspension, 200 ng plasmid DNA was added. The mixture was then incubated for $15 \mathrm{~min}$ on ice and subsequently electroporated with a Gene Pulser Plus pulse controller (Bio-Rad, Richmond, CA, USA), using the following settings: $2.5 \mathrm{kV}$, $200 \Omega$, and $25 \mu \mathrm{F}$. Transformants carrying the $g f p$ marker were selected on King's B medium containing $50 \mu \mathrm{g} / \mathrm{mL}$ kanamycin. Colonies of the $g f p$-marked strain (AF7gfp) were identified under ultraviolet light. To determine the stability of the pCM88 plasmid, the Pseudomonas AF7gfp strain was grown in culture medium for several generations without selective pressure. Inoculation of rice seeds was performed as previously described in the section Plant growth and greenhouse inoculation. Bacterial colonization was examined using a fluorescence microscope (DM 5000B Leica) and high-resolution scanning electron microscopy (Leo 982 GEMINI DMS, Zeiss e Leica), as specified by the manufacturer.

\section{Immobilization of Pseudomonas AF7 in alginate}

Beads were manufactured using sodium alginate from Macrocystis pyrifera (Sigma, St. Louis, MO, USA) as previously described by Russo et al., 2001. For this process, $10^{9} \mathrm{CFU} /$ $\mathrm{mL}$ bacterial cells were resuspended in a sterile solution of $2 \mathrm{M}$ calcium chloride. The moist beads were dried for approximately $24 \mathrm{~h}$ in a laminar flow hood at $28^{\circ} \mathrm{C}$. The dimensions of the microbeads that were obtained were evaluated using a scanning electron microscope (Philips SEM 505 at $10 \mathrm{kV}$ ). The survival of Pseudomonas isolate AF7 in microbeads was periodically monitored for 12 months. To determine the percentage of the culture encapsulated, the microbeads were completely dissolved in a sterile $1 \%$ sodium citrate solution $(\mathrm{pH} 6.5)$ for $30 \mathrm{~min}$ at room temperature. The suspensions were serially diluted into sterile physiological solution $(0.9 \% \mathrm{NaCl})$ and plated on sucrose asparagine agar (Russo et al., 2001) supplemented with $25 \mu \mathrm{g} / \mathrm{mL}$ chromogenic substrate X-gal. Blue colonies were counted after 4 to 5 days of incubation at $28^{\circ} \mathrm{C}$. All experiments were performed in triplicate.

\section{RESULTS}

Using the described protocol, 30 different strains of bacteria that were resistant to high concentrations of the herbicide propanil were isolated from rice rhizosphere. These bacteria had likely adapted to be resistant to the herbicide propanil. It is possible that the selective pressure exerted by the herbicide, which had been applied to the soil for several decades, permitted the growth of certain bacterial groups. Three genera of bacteria associated with the rice rhizosphere were found to be capable of growing in culture medium containing propanil: Pseudomonas, Serratia and Acinetobacter (Figure 1). The largest number of isolates, approximately $86.7 \%$, belonged to the genus Pseudomonas (P1SR3, P1SR4, P2SR3, P2SR4, P3SR2, P4SR1, P4SR2, P4SR3, P4SR8, P4SR9, P4SR9_1, P5SR1, P5SR2, P5SR3, P6SR2, P6SR4, P7SR2, P8SR2, P9SR1, P9SR2, P9SR3, P9SR4, P9SR5, P10SR1, P10SR3, P10SR5), followed by Serratia, with approximately $10.0 \%$ of the isolates (P6SR5, P6SR6, P6SR7), and Acinetobacter, with a single isolate (P3SR1) corresponding to $3.3 \%$ of the total community of propanil-resistant rhizobacteria isolated in this work. Rhizobacteria were identified by sequencing the 16S rDNA gene, which is considered to be one of the most informative methods for studying phylogeny and microbial ecology because it allows for the identification and study of genetic diversity. 
A

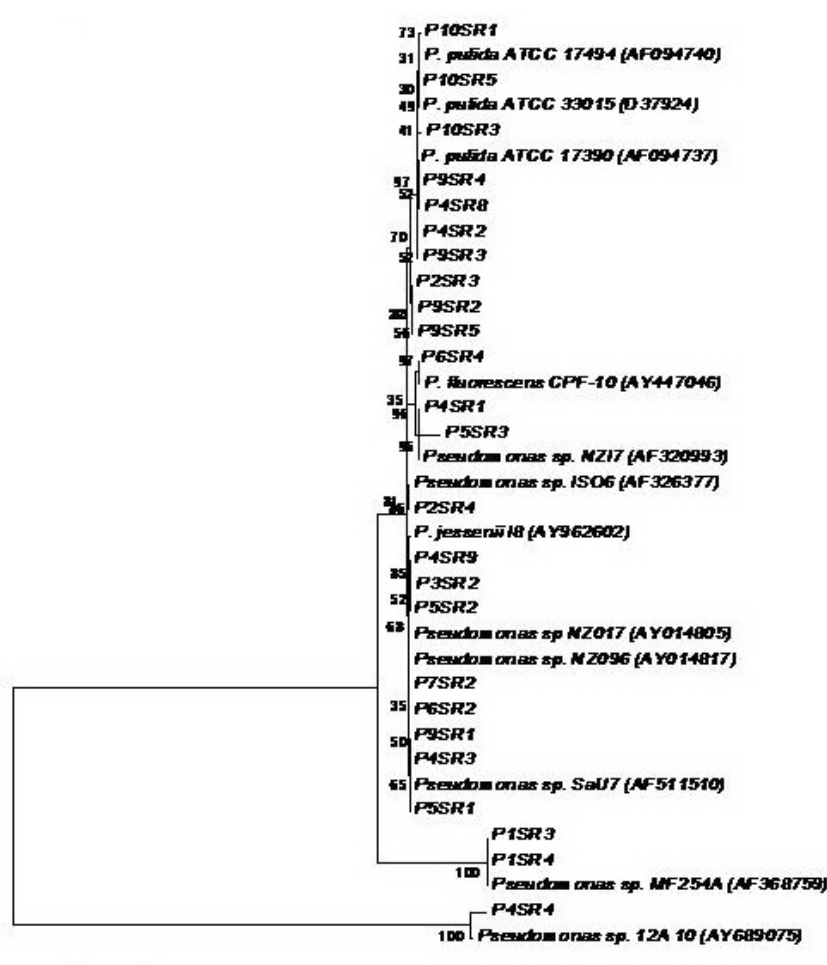

B

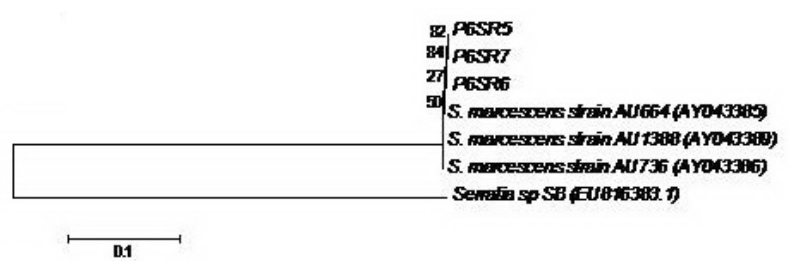

C

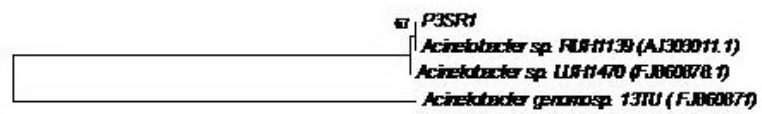

n1

D

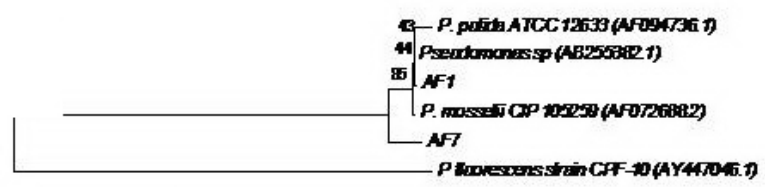

$\mathbf{0 1}$

Figure 1. Phylogenetic trees based on 16S rDNA sequences showing the position of the isolates from this study compared to that of certain related genera. A. Pseudomonas; B. Serratia; C. Acinetobacter, and D. Pseudomonas isolated from a bioreactor with propanil as the sole source of carbon. 
A total of 30 strains (named AF1 to AF30) were isolated using an aerobic culture method in a bioreactor containing propanil as the sole source of carbon. Isolated strains were subcultured and purified in chemostatic medium, previously described. The selected isolates were studied for their level of tolerance to propanil. The bacteria were capable of tolerating the highest concentration of propanil $(10 \mathrm{mg} / \mathrm{L})$. Phylogenetic analysis of the isolates showed the presence of only two species, grouped with isolates AF1 or AF7 and belonging to the genus Pseudomonas (Figure 1). The degradation of propanil by isolated rice rhizosphere microflora also showed that several organisms had adapted to use this chemical after repeated rounds of exposure in the field (Hoagland et al., 1994).

\section{Biodegradation}

Using the conditions for growth and chromatographic analysis described above, propanil was found to have an average peak retention time of $7.45 \mathrm{~min}$. The matrices and reagents used in the analysis did not cause any interference. We chose the AF7 and AF1 strains for further analysis, as they grew the best in the chemostactic medium. Strains AF7 and AF1 were found to grow faster in culture medium containing the herbicide propanil as the sole carbon source than in medium containing glucose. AF7 exhibited efficient degradation of the herbicide propanil, as it was only possible to recover approximately $40 \%$ of the propanil that was added to the medium (60\% degradation). The AF1 strain was less efficient, as it was possible to recover approximately $60 \%$ of the propanil that was added to the culture medium (Figure 2). These results show that the isolate AF7 degrades propanil more efficiently after 15 days of growth.

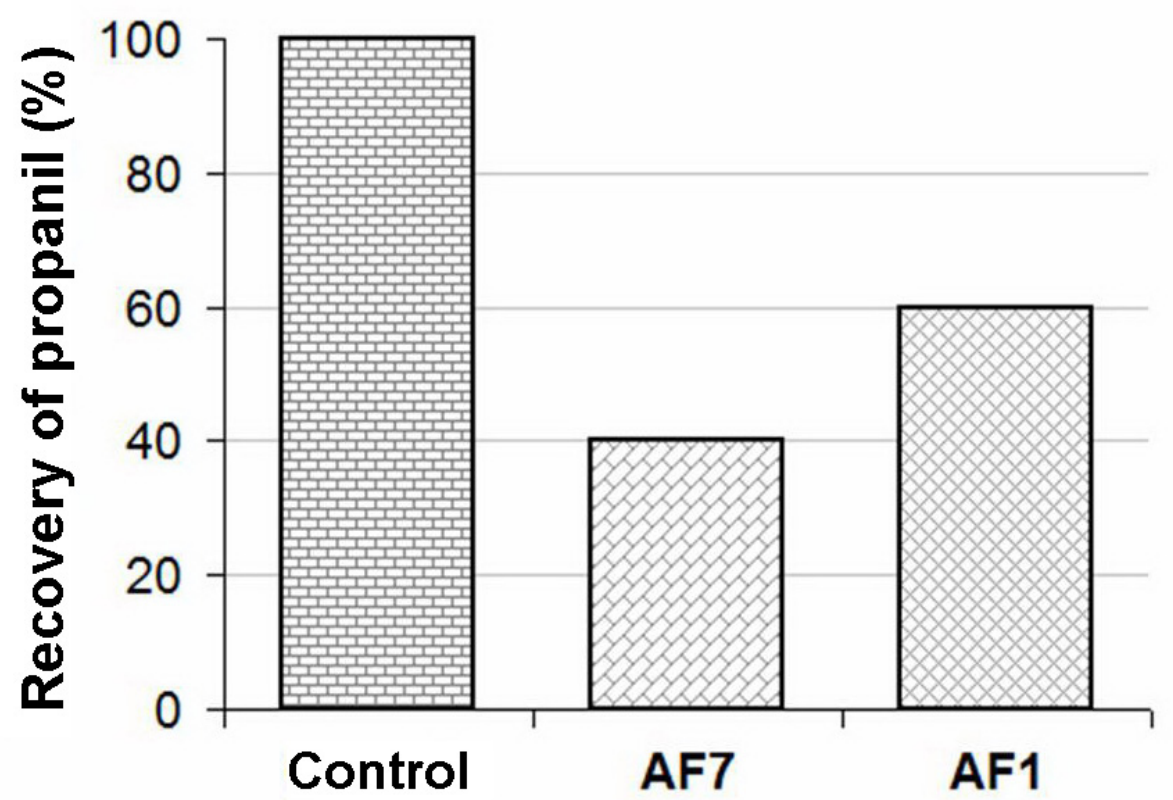

Figure 2. Percentage of propanil recovered after 15 days of growth in chemotactic medium with propanil as the sole carbon source. 


\section{Screening and selection of bacterial strains}

A total of 32 bacterial strains were analyzed for their abilities to produce IAA, solubilize phosphate and fix nitrogen in vitro. The highest number of isolates belonged to the genus Pseudomonas (29); the majority of these isolates (65.5\%; P1SR3, P2SR4, P4SR1, P4SR2, P4SR3, P4SR9, P4SR9_1, P5SR1, P5SR3, P6SR2, P7SR2, P8SR2, P9SR1, P9SR3, P9SR4, P9SR5, P10SR3, AF1, and AF7) were able to fix nitrogen, solubilize phosphate and produce auxin. Three isolates were found to fix nitrogen and solubilize phosphate (P3SR2, P4SR8 and P10SR1). Three isolates produced only IAA (P1SR4, P2SR3 and P10SR5), two isolates only fixed nitrogen (P6SR4 and P9SR2) and one isolate (P5SR3) produced IAA and solubilized phosphate. The genus Serratia had two isolates (P6SR5 and P6SR6) that fixed nitrogen and produced IAA but did not solubilize phosphate. The isolate P6SR7 only fixed nitrogen. The single isolate from the genus Acinetobacter (P3SR1) only fixed nitrogen.

\section{Promotion of plant growth by rhizobacteria}

Fifteen days after germination, inoculation with rhizobacteria showed satisfactory results: plants inoculated with bacteria were more developed than control plants. Strains AF1, AF7 and Acc produced significantly different plant height values (Figure 3) compared to the control when grown in soil with $25 \mu \mathrm{g} / \mathrm{mL}$ propanil (the controls exhibited less development). There was no significant difference when comparing strains AF7 and AF1 to Acc (a species already studied as a plant growth promoter), but there was a difference in the height of plants grown at different concentrations of propanil or without any propanil.

At the middle concentration level $(2.5 \mu \mathrm{g} / \mathrm{mL})$, AF7 exhibited a higher efficiency than the other strains. As for the number of roots (Figure 3), there was no difference between strains when propanil was used at either concentration $(2.5$ or $25 \mu \mathrm{g} / \mathrm{mL})$, but all isolates at both concentrations showed a larger number of roots than did control plants grown without bacteria. Plants treated with rhizobacteria from soil containing propanil were significantly different compared to the control plants. This result highlights the efficiency of microorganisms that may degrade propanil and their importance for rice yield. All treatments with selected strains produced superior results compared to treatments without inoculation with microorganisms.

All plants that were treated with inoculated soil and propanil produced more biomass than did uninoculated plants in soil without propanil (Figure 3).

\section{Transformation and reisolation of strain AF7-gfp}

The efficiency of the transformation of strain AF7 with the pCM88 plasmid was approximately $1.6 \times 10^{4}$ transformants $/ \mu \mathrm{g}$ DNA, indicating that the plasmid was introduced at a high efficiency. It was observed that the pCM88 plasmid highly expresses the $g f p$ gene (Figure $4 \mathrm{~A}$ ). We analyzed the transformed isolates, chosen at random, and found that the pCM88 plasmid stably expressed $g f p$ in strain AF7-gfp after several generations without antibiotic selection. This strain can be used with plants to study colonization. When inoculating on rice seeds, the AF7-gfp strain was able to colonize roots and root hairs. Abundant colonization was observed using scanning electron microscopy, with the strain occupying specific niches, such as the fissures of rice roots (Figure 4B). Grouping was also observed in the form of colonies, 
which formed in mucilage and single cells (Figure 4B and 4C). We recovered approximately $1.8 \times 10^{5} \mathrm{CFU}$ per $\mathrm{g}$ of rhizosphere soil 30 days after seed germination and $7.2 \times 10^{4} \mathrm{CFU}$ per $g$ of rhizosphere soil after 75 days. There was a reduction in the population of genetically modified bacteria in the soil at this time.

A

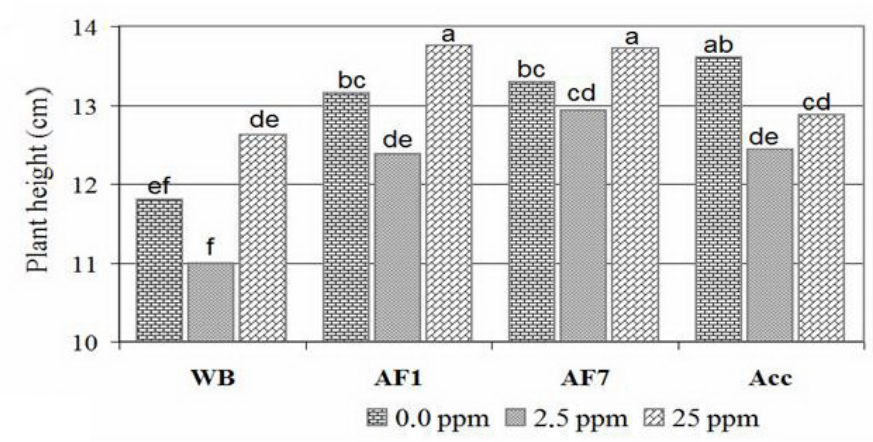

B

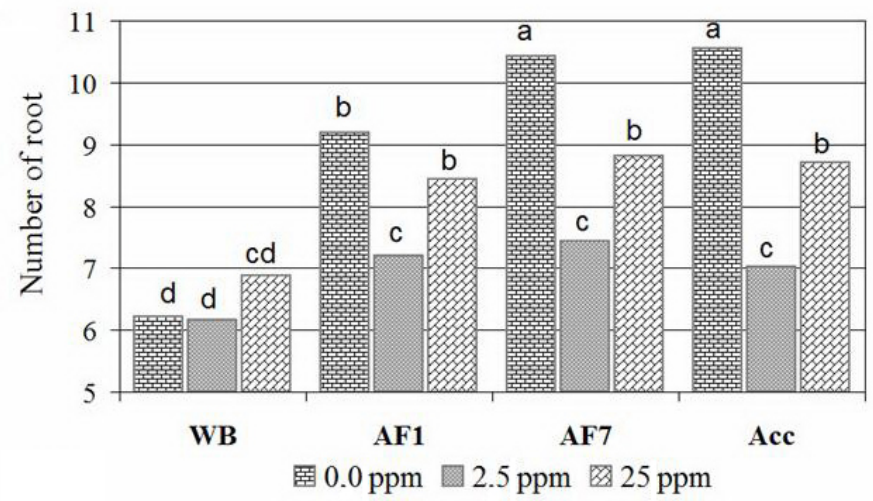

C

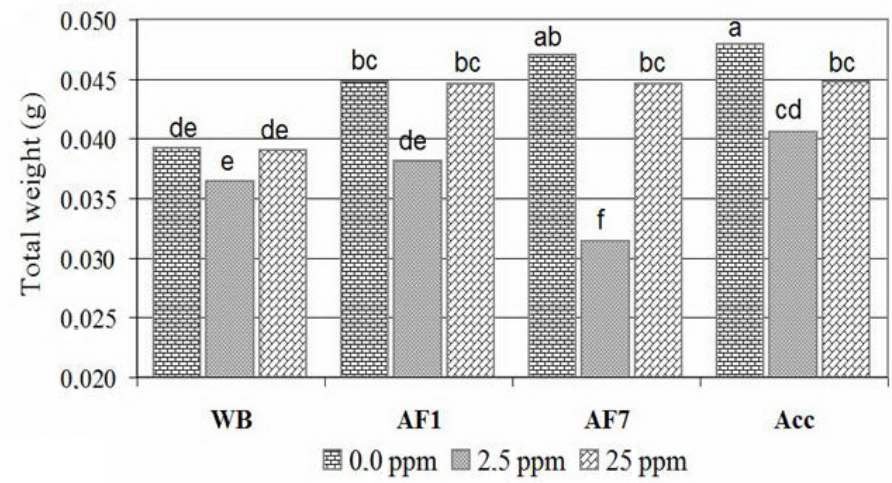

Figure 3. Plant development in the presence of different concentrations of propanil 15 days after inoculation with AF7 or AF1 (Pseudomonas) or Acc (Acinetobacter), where WB refers to control without bacteria. The height of the plant (A), number of roots $(\mathbf{B})$, and plant weight $(\mathbf{C})$ are shown. 


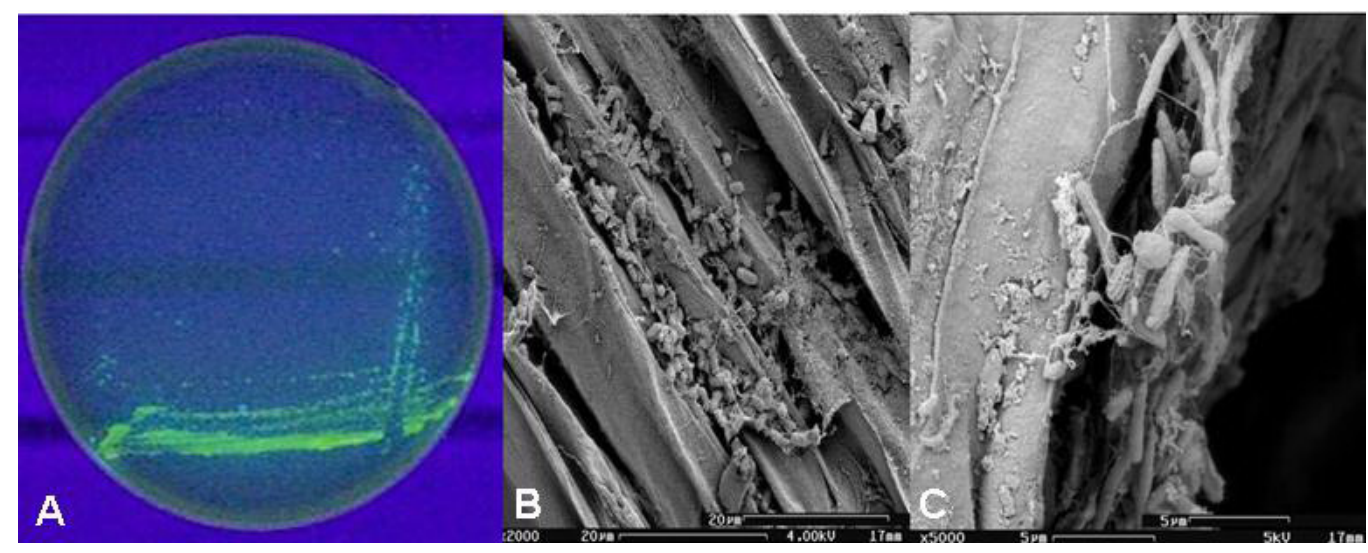

Figure 4. Strain AF7 producing GFP under ultraviolet light (A) and electron micrographs showing rice root colonization by strain AF7 (B and C).

\section{Strain AF7-gfp can be immobilized within alginate beads}

We encountered several problems when forming pellets with the AF7-gfp strain using formulations containing $2 \%$ calcium alginate and kaolin at concentrations of 1 and $2 \%$. We observed deformed pellets and large quantities of pellets that adhered to one another and did not separate after drying. These properties made the formulation irregular and difficult to use and reduced the quality of the final product. Concentrations of 3 and $5 \%$ kaolin, however, produced reproducible results, showing $100 \%$ viability for germination of the pellets (Figure 5B). This viability was observed for samples placed at a temperature of $28^{\circ} \mathrm{C}$ and for samples stored at $4{ }^{\circ} \mathrm{C}$, but the pellets stored at $2^{\circ} \mathrm{C}$ were kept at low humidity to prevent the development of other microorganisms. Typically, low storage temperatures ensure the preservation of microbial products. The surface of the pellets had a sponge-like appearance with cavities (Figure 5C) that created a microenvironment for the bacteria to settle, ensuring viability in storage or in the soil.

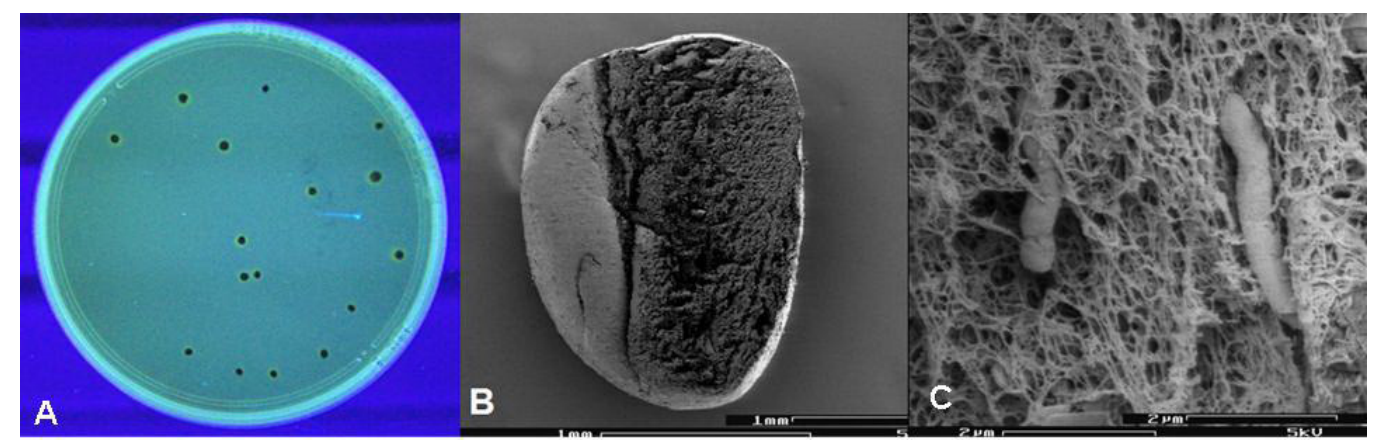

Figure 5. Growth of bioencapsulated Pseudomonas on a plate medium (A) and electron micrographs of alginate beads showing in (B) the morphological aspect and in $(\mathbf{C})$ immobilized cells viewed at high magnification. 


\section{DISCUSSION}

Understanding the composition of the bacterial populations that are associated with rice plants will be fundamental to understanding how biological processes associated with bacteria are influenced by the environment and, consequently, have important biotechnological implications. The phylogenetic analysis presented here revealed a close relationship among the field isolates, supporting the hypothesis that there is a selective pressure on the bacterial population in the rhizosphere. Most bacteria were found to belong to the genus Pseudomonas, followed by Serratia and Acinetobacter. Bacteria often possess the ability to degrade xenobiotic compounds (Vamsee-Krishna et al., 2006; Cycon et al., 2009). The degradation of propanil by the rice rhizosphere bacteria shows that these organisms had adapted to metabolize this chemical after repeated rounds of exposure in the field (Sarkar et al., 2010; Yao et al., 2011). Earlier studies have suggested that pesticides applied to soil are often degraded more rapidly following repeated application to the same site, where the soil then possesses bacteria capable of degrading the contaminants (Witzig et al., 2006). Based on the morphological and biochemical characterization of the isolates, we identified the cultures as belonging to the versatile bacterial genus Pseudomonas. Previous reports have suggested that this genus can degrade a number of chemicals and pesticides, including oxadiazon (Garbi et al., 2006), sulfonylurea (Ma et al., 2009), p-nitrophenol (Zheng et al., 2009) and phenolic compounds (Li et al., 2010). Thus, this genus has immense nutritional diversity. Pseudomonas spp are common soil bacteria that are easily cultured from most agricultural soils and rhizospheres. They have been studied intensely because of their ability to promote plant growth, either by directly stimulating the plant or by suppressing the growth of root pathogens (Lawongsa et al., 2008). Pseudomonas species are characterized by an unprecedented tolerance for toxic compounds (Kalwaslińska et al., 2008) and have long been recognized for their genetic, physiological and functional diversity (Silby et al., 2009). The ability of the strain AF7 to grow and degrade propanil as the sole carbon and energy source is illustrated in Figure 2 This behavior makes this strain a promising agent for the bioremediation of propanil at contaminated sites (HatamianZarmi et al., 2009).

The rhizosphere is a complex environment in which roots are influenced by the physical, chemical and biological properties of the soil, and both have a significant influence on the capacity of the roots to acquire nutrients. Roots also interact extensively with soil microorganisms, which further impact plant nutrition, either directly by influencing nutrient availability and uptake or indirectly through plant growth promotion (Richardson et al., 2009).

In this study, both inoculated and uninoculated plants were subjected to different concentrations of propanil, and each exhibited different growth properties. In general, with an increasing concentration of contaminants, a progressive decrease in plant growth is observed, suggesting that the contaminants are toxic. The bioinoculant can significantly reduce the toxicity and, consequently, increase overall plant growth. Studies have shown that lower concentrations of pesticides are less toxic to plants. This effect is more pronounced as concentrations increase above recommended levels (Weyens et al., 2010). In contrast, we found that lower concentrations of propanil are more toxic, indicating that different pesticides have variable effects. Ahemad and Khan (2010) showed that the application of $3900 \mu \mathrm{g}$ pyriproxyfen per $\mathrm{kg}$ of soil (three times the recommended dose) results in the highest toxicity and decreases root nitrogen, shoot nitrogen, root phosphorus, shoot phosphorus, seed yield, and grain pro- 
tein compared to the control. Interestingly, when the inoculant strain MRP1 was used at any concentration of the two insecticides, it was found to significantly increase $(P \leq 0.05)$ the measured variables (plant dry weight, nodule number, dry nodule biomass, leghemoglobin, nitrogen and phosphorus uptake, seed yield, and grain protein) compared to the plants grown in sandy clay loam soils treated with the same amount of each insecticide (without inoculant). For instance, three times the recommended dose of pyriproxyfen in conjunction with the MRP1 strain was found to show the highest stimulatory effect and increase the root nitrogen, shoot nitrogen, root phosphorus, shoot phosphorus, seed yield and grain protein compared to the plants grown in soil treated with three times the recommended dose of pyriproxyfen alone (Ahemad and Khan, 2010). The benefits of rhizobacteria that promote plant growth, particularly those of the genus Pseudomonas, for enhancing growth and improving plant health are well known (Kandasamy et al., 2009). Previous studies with strains SF4c and SF10b have demonstrated that both are able to promote rice growth under greenhouse conditions, probably because they exhibit some PGPR traits, such as solubilizing phosphorus, fixing atmospheric nitrogen, and producing plant hormones (Fischer et al., 2010). We analyzed the potential for using the plant growth-promoting rhizobacterial AF7 strain as a vehicle for the study of colonization and gene expression. Our results led us to conclude that the bacteria survive in this environment in sufficient numbers and that the in situ expression of the $g f p$ gene takes place in both bacterial microcosms. In addition, the AF7-gfp strain may compete successfully with other microorganisms for exudate nutrients and efficiently colonize the plant root. Although additional experiments are necessary to analyze these potential properties of the recombinant strain, it is known that Pseudomonas spp are the most abundant rhizosphere species (Silby et al., 2009). van Overbeek et al. (1997) found that a Pseudomonas strain carrying reporter genes colonized the wheat rhizosphere, and several successful rhizoremediation experiments have been carried out with Pseudomonas strains to clean up soils that are polluted with propanil (Zablotowicz et al., 2001). Monti et al. (2005) showed the possibility of assessing the ecology of inoculants in the rhizosphere by studying differential reporter gene expression and adaptability under field conditions. With this approach, it is possible to gain fundamental insight into the process of root colonization under field conditions, allowing for the development of strategies to improve bacterial inoculants.

The results obtained here indicate that the encapsulation within alginate followed by drying did not affect bacterial viability. The main advantages of alginate inoculants are their nontoxic nature, their ability to degrade in the soil, and their slow release of the entrapped microorganisms into the soil. This slow release protects the microorganisms against many environmental stresses and allows cells to continue growth and metabolism (Yabur et al., 2007). Two plant growth-promoting bacteria, Azospirillum brasilense $\mathrm{Cd}$ and Pseudomonas fuorescens 313, which were immobilized in 1983 in two types of alginate beads (with and without a skim-milk supplement) and later dried and stored at ambient temperature for 14 years, were recoverable in 1996. The population within each type of bead had decreased, yet significant numbers had survived $10^{6}$ to $10^{5} \mathrm{CFU} / \mathrm{g}$ beads (Bashan and Gonzalez, 1999). P. fluorescens F113 LacZY cells have also been encapsulated in alginate; their survival and ability to colonize sugar beets were evaluated previously. The capability of the encapsulated cells to produce the antifungal metabolite 2,4-diacetylphloroglucinol was not significantly affected by 12 months of storage (Russo et al., 2001). The growth and activity of any given soil microorganism depends not only on its genetic characteristics, but also on numerous environmental factors that 
govern its intrinsic activities (Devliegher et al., 1995). Understanding the factors that affect the population dynamics of microorganisms and their temporospatial relationships in natural ecosystems is of primary importance for the effective use of microorganisms as plant growth promoters, biological controllers, and bioremediation agents. In the past few years, however, soil has been subject to both use and handling pressures due to certain agricultural practices, which lead to its degradation (Rosas et al., 2009). The use of plant growth-promoting rhizobacteria as inoculants constitutes a biological alternative for sustainable production.

\section{REFERENCES}

Ahemad M and Khan MS (2010). Comparative toxicity of selected insecticides to pea plants and growth promotion in response to insecticide-tolerant and plant growth promoting Rhizobium leguminosarum. Crop Prot. 29: 325-329.

Andreote FD, Gullo MJ, de Souza Lima AO, Maccheroni W Jr, et al. (2004). Impact of genetically modified Enterobacter cloacae on indigenous endophytic community of Citrus sinensis seedlings. J. Microbiol. 42: 169-173.

Bashan Y and Gonzalez LE (1999). Long-term survival of the plant-growth-promoting bacteria Azospirillum brasilense and Pseudomonas fluorescens in dry alginate inoculant. Appl. Microbiol. Biotechnol. 51: 262-266.

Bergey DH, Holt JG and Krieg NR (1984). Bergey’s Manual of Determinative Bacteriology. 2nd edn. Williams and Wilkins, Baltimore.

Cycon M, Wojcik M and Piotrowska-Seget Z (2009). Biodegradation of the organophosphorus insecticide diazinon by Serratia sp. and Pseudomonas sp. and their use in bioremediation of contaminated soil. Chemosphere 76: 494-501.

Devliegher W, Arif M and Verstraete W (1995). Survival and Plant Growth Promotion of Detergent-Adapted Pseudomonas fluorescens ANP15 and Pseudomonas aeruginosa 7NSK2. Appl. Environ. Microbiol. 61: 3865-3871.

Dobereiner J, Baldani VLD and Baldani JI (1995). Como Isolar e Identificar Bactérias Diazotróficas de Plantas NãoLeguminosas. EMBRAPA Press, Brasília.

Fischer SE, Jofre EC, Cordero PV, Gutierrez Manero FJ, et al. (2010). Survival of native Pseudomonas in soil and wheat rhizosphere and antagonist activity against plant pathogenic fungi. Antonie Van Leeuwenhoek 97: 241-251.

Garbi C, Casasus L, Martinez-Alvarez R, Ignacio RJ, et al. (2006). Biodegradation of oxadiazon by a soil isolated Pseudomonas fluorescens strain CG5: Implementation in an herbicide removal reactor and modelling. Water Res. 40: $1217-1223$.

Hatamian-Zarmi A, Shojaosadati SA, Vasheghani-Farahani E and Hosseinkhani S (2009). Extensive biodegradation of highly chlorinated biphenyl and Aroclor 1242 by Pseudomonas aeruginosa TMU56 isolated from contaminated soils. Int. Biodeterior. Biodegradation 63: 788-794.

Hoagland RE, Zablotowicz RM and Locke MA (1994). Propanil Metabolism by Rhizosphere Microflora. Bioremediation Through Rhizosphere Technology (Anderson TA and Coats JR, eds.). American Chemical Society, Washington, 160-183.

Kalwaslińska A, Kesy J and Donderski W (2008). Biodegradation of carbendazim by epiphytic and neustonic bacteria of eutrophic Chelmzynskie Lake. Pol. J. Microbiol. 57: 221-230.

Kandasamy S, Loganathan K, Muthuraj R and Duraisamy S (2009). Understanding the molecular basis of plant growth promotional effect of Pseudomonas fluorescens on rice through protein profiling. Proteome Sci. 7: 47.

Kuklinsky-Sobral J, Araujo WL, Mendes R, Geraldi IO, et al. (2004). Isolation and characterization of soybean-associated bacteria and their potential for plant growth promotion. Environ. Microbiol. 6: 1244-1251.

Lawongsa P, Boonkerd N, Wongkaew S and Gara FO (2008). Molecular and phenotypic characterization of potential plant growth-promoting Pseudomonas from rice and maize rhizospheres. World J. Microbiol. Biotechnol. 24: 1877-1884.

Li Y, Li J, Wang C and Wang P (2010). Growth kinetics and phenol biodegradation of psychrotrophic Pseudomonas putida LY1. Bioresour. Technol. 101: 6740-6744.

Ma JP, Wang Z, Lu P, Wang HJ, et al. (2009). Biodegradation of the sulfonylurea herbicide chlorimuron-ethyl by the strain Pseudomonas sp. LW3. FEMS Microbiol. Lett. 296: 203-209.

Monti MR, Smania AM, Fabro G, Alvarez ME, et al. (2005). Engineering Pseudomonas fluorescens for biodegradation of 2,4-dinitrotoluene. Appl. Environ. Microbiol. 71: 8864-8872.

Pichon V, Krasnova AI and Hennion MC (2004). Development and characterization of an immunoaffinity solid-phaseextraction sorbent for trace analysis of propanil and related phenylurea herbicides in environmental waters and in beverages. Chromatographia 60: S221-S226.

Richardson AE, Barea JM, McNeill AM and Prigent-Combaret C (2009). Acquisition of phosphorus and nitrogen in the rhizosphere and plant growth promotion by microorganisms. Plant Soil. 321: 305-339. 
Rosas SB, Avanzini G, Carlier E and Pasluosta C (2009). Root colonization and growth promotion of wheat and maize by Pseudomonas aurantiaca SR1. Soil Biol. Biochem. 41: 1802-1806.

Russo A, Basaglia M, Tola E and Casella S (2001). Survival, root colonisation and biocontrol capacities of Pseudomonas fluorescens F113 LacZY in dry alginate microbeads. J. Ind. Microbiol. Biotechnol. 27: 337-342.

Sarkar S, Seenivasan S and Asir RP (2010). Biodegradation of propargite by Pseudomonas putida, isolated from tea rhizosphere. J. Hazard. Mater. 174: 295-298.

Silby MW, Cerdeno-Tarraga AM, Vernikos GS, Giddens SR, et al. (2009). Genomic and genetic analyses of diversity and plant interactions of Pseudomonas fluorescens. Genome Biol. 10: R51.

Tamura K, Dudley J, Nei M and Kumar S (2007). MEGA4: Molecular Evolutionary Genetics Analysis (MEGA) software version 4.0. Mol. Biol. Evol. 24: 1596-1599.

Tidswell EC, Russell NJ and White GF (1996). Ether-bond scission in the biodegradation of alcohol ethoxylate nonionic surfactants by Pseudomonas sp. strain SC25A. Microbiology 142: 1123-1131.

Vamsee-Krishna C, Mohan Y and Phale PS (2006). Biodegradation of phthalate isomers by Pseudomonas aeruginosa PP4, Pseudomonas sp. PPD and Acinetobacter lwoffii ISP4. Appl. Microbiol. Biotechnol. 72: 1263-1269.

van Overbeek LS, van Veen JA and van Elsas JD (1997). Induced reporter gene activity, enhanced stress resistance, and competitive ability of a genetically modified Pseudomonas fluorescens strain released into a field plot planted with wheat. Appl. Environ. Microbiol. 63: 1965-1973.

Vidali M (2001). Bioremediation. An overview. Pure Appl. Chem. 73: 1163-1172.

Weyens N, Truyens S, Dupae J, Newman L, et al. (2010). Potential of the TCE-degrading endophyte Pseudomonas putida W619-TCE to improve plant growth and reduce TCE phytotoxicity and evapotranspiration in poplar cuttings. Environ. Pollut. 158: 2915-2919.

Witzig R, Junca H, Hecht HJ and Pieper DH (2006). Assessment of toluene/biphenyl dioxygenase gene diversity in benzene-polluted soils: links between benzene biodegradation and genes similar to those encoding isopropylbenzene dioxygenases. Appl. Environ. Microbiol. 72: 3504-3514.

Yabur R, Bashan Y and Hernandez-Carmona G (2007). Alginate from the macroalgae Sargassum sinicola as a novel source for microbial immobilization material in wastewater treatment and plant growth promotion. J. Appl. Phycol. 19: 43-53.

Yao XF, Khan F, Pandey R and Pandey J (2011). Degradation of dichloroaniline isomers by a newly isolated strain, Bacillus megaterium IMT21. Microbiology 157: 721-726.

Zablotowicz RM, Locke MA, Hoagland RE, Knight SS, et al. (2001). Fluorescent Pseudomonas isolates from Mississippi Delta oxbow lakes: in vitro herbicide biotransformations. Environ. Toxicol. 16: 9-19.

Zheng Y, Liu D, Xu H and Zhong Y (2009). Biodegradation of p-nitrophenol by Pseudomonas aeruginosa HS-D38 and analysis of metabolites with HPLC-ESI/MS. Int. Biodeterior. Biodegradation 63: 1125-1129. 